\title{
Implementing Effective Learning with Ubiquitous Learning Technology During Coronavirus Pandemic
}

\author{
Hosam F. El-Sofany ${ }^{1,2, *}$ and Samir A. El-Seoud ${ }^{3}$ \\ ${ }^{1}$ King Khalid University, Abha, Kingdom of Saudi Arabia \\ ${ }^{2}$ Cairo Higher Institute for Engineering, Computer Science and Management, Cairo, Egypt \\ ${ }^{3}$ British University in Egypt-BUE, Faculty of Informatics and Computer Science, Cairo, Egypt \\ ${ }^{*}$ Corresponding Author: Hosam F. El-Sofany. Email: helsofany@kku.edu.sa \\ Received: 14 March 2021; Accepted: 30 April 2021
}

\begin{abstract}
Ubiquitous computing supports U-learning to develop and implement a new educational environment that provides effective and interactive learning to students wherever they are. This study aims to present a qualitative evaluation for using U-learning instead of traditional education to avoid the spread of the Coronavirus pandemic. The authors introduce a UTAUT (Unified Theory of Acceptance and Use of Technology) model to assess the capability of the given factors that are expected to affect the learners' intention and behavior for accepting the U-learning technology for full E-learning. The research study shows a promising impact on the use of U-learning apps for implementing their learning activities in both the present and coming stage. The study also presents the descriptive statistics that affect the students' answers by using U-learning while implementing learning assignments including exams, projects, forums, essays, presentations, and laboratories. The research experiments demonstrate both the composite reliability (CR) and the average variance extracted (AVE) of the presented paradigm. The experimental results have shown that (1) the factor loadings $\geq 0.75, \mathrm{CR} \geq 0.9$, and $\mathrm{AVE} \geq 0.75$, which present appropriate proof for the validity and reliability of the proposed model, and (2) the total average of students that accept the U-learning is $82.99 \%$, and who disagree is $8.13 \%$, while who neither agree nor disagree is $6.44 \%$.
\end{abstract}

Keywords: Ubiquitous learning; U-learning; E-learning; M-learning; COVID-19 pandemic; coronavirus; UTAUT model

\section{Introduction}

We can consider ubiquitous computing as a recent innovation in the world of IT, AI, IoT, cloud computing, and communication. It relates to several connected E-devices such as computers, mobiles, smart cards, sensor networks, etc., which all have computation and communication capabilities. These E-devices may connect with sensors and actuators, which allow individuals to communicate and interact with several activities in their living environment. This new technique increases the possibility of having good and satisfactory communication abilities that provide secure access and data exchange within the

This work is licensed under a Creative Commons Attribution 4.0 International License, which permits unrestricted use, distribution, and reproduction in any medium, provided the original work is properly cited. 
community. According to this recent technology, educational techniques have advanced from electronic and mobile learning to ubiquitous learning [1]. U-learning depends on ubiquitous technology. Ubiquitous computing supports U-learning to develop and implement a new U-learning environment that provides education to students everywhere.

The proposed UTAUT paradigm presents the learners' assessment analysis and feedback concerning the use of present LMS systems. The five essential factors for the proposed UTAUT approach are Performance Expectancy, Effort Expectancy, Social Influence, Facilitating Conditions, and Behavioral Intentions [2]. The first four factors denoted by (PE, EE, SI, FC) deal with the intention and behavior of the learners that are applied in the recent U-learning apps, while the fifth factor denoted by (BI) deals with their behavior only. The proposed model is influenced by various factors regarding the use of the new apps and technologies such as gender, age, experience, and voluntariness. This paper investigates four research questions to evaluate the objectives of the study.

i) To what extent do students find the available U-learning system beneficial and useful for supporting and enhancing their learning and communication?

ii) What is the degree of difficulty that students face while using the interactive U-learning tools provided by administrators?

iii) To what extent do professors and students affect other students' intentions to use the available U-learning tools for learning and communication?

iv) What is the effect of technical support provided to students to use the present U-learning technology effectively?

This paper aims to present a qualitative evaluation for using U-learning instead of traditional learning due to the diffusion of coronavirus pandemic. The study proposes a UTAUT model to assess the capability of the given factors that are expected to affect the learners' intention and behavior for accepting the U-learning technology for full E-learning. The research study shows a promising influence regarding the usage of U-learning apps for fulfilling their learning objectives today or in the future. The study also presents the descriptive statistics that affect the students' answers by using U-learning while implementing learning assignments including exams, projects, forums, essays, presentations, and laboratories.

\section{Ubiquitous Computing and Ubiquitous Learning}

Ubiquitous computing is considered a recent direction of implementing digital transformation integrated technologies. It refers to integrated technologies placed in the background of our lives [1]. This new technology provides individuals with an integrated cloud environment containing computing, software, hardware, databases, and application services available anytime and anywhere [3]. Communication and IT are considered the fundamental technologies that form ubiquitous computing. Nowadays, the continuous development of communication and computing sciences has helped in the expansion and improvement of ubiquitous computing. Recently, in the computing discipline, there are several developed computing technologies such as cloud computing, 5G networks, blockchain, Internet of Things (IoT), cybersecurity, sensors, actuators, mobiles, and personal digital assistants (PDAs). The communication between the student and the learning environment is the source of interactive knowledge, so many researchers have found that learning by practice is the leading direction in education. Learning by practice focuses on implicit practices, and courses that are learned implicitly and only need the professor's experience [4]. The learning process through the U-learning environment becomes easier and more interactive. For example, a student can use a mobile, computer, or any wireless device to connect and access the E-learning management system through wireless network technology [5-7].

Ubiquitous learning is a modern, interactive, and integrated learning model. The U-learning environment is created to provide learners with learning activities embedded in their daily lives, 
depending on the development of ubiquitous computing capabilities (e.g., wireless communication, cloud computing, computing power, AI, IoT, and software engineering) [8]. Researchers have various perspectives in defining U-learning, due to the continuous changes in communication and learning technologies [9]. Therefore, researchers categorize the learning environments into four categories of ubiquitous computing including computer-assisted, pervasive, mobile, and ubiquitous- learning [10]. Computer-assisted learning systems refer to any use of computers to aid or support the education of individuals. However, it provides low mobility, unlike M-learning which focuses on increasing learners' capability and providing a high mobility learning environment [8]. In pervasive learning, the communication between embedded devices and the learning environment plays a vital role in obtaining information from the learners. As a result, learning availability is very limited, and these limitations have been solved by U-learning through the mobility applications, tools, and devices embedded into the learning environment. This digital integration among communication devices and embedded systems allow learners to learn while they are on the move [11].

Ubiquitous learning is represented by the formula: U-learning $=\sum(E+M)$ learning $)$ [12]. This shows that U-learning consists of M-learning and E-learning activities [13]. Ubiquitous learning is defined as "the learning applied anywhere and anytime". This definition refers to the provision of learning resources and activities through any mobile devices connected by wireless networks. Additionally, mobile learning refers to "the implemented learning via wireless tools (e.g., mobile, PDAs, or laptops)". The two previous definitions are almost the same, which may cause some confusion for the reader. Therefore, U-learning should be defined differently to avoid any possible confusion or misunderstanding while implementing it [14]. Hence, we define U-learning generally as "The delivered learning using ubiquitous computing technology" [15]. This definition is also suitable for M-learning. Therefore, we have used the expression "context-aware ubiquitous learning" to differentiate between ubiquitous and mobile learning definitions. Finally, U-learning is an integration of electronic and mobile learning with some supplemental technologies and tools such as internet connections, mobile communication systems, GPS and GIS systems, sensor network and natural user interfaces, virtual reality, cloud computing, mobile computing, artificial intelligence, and context-based computing that provide interactive and context-based applications, as shown in Fig. 1 [15,16].

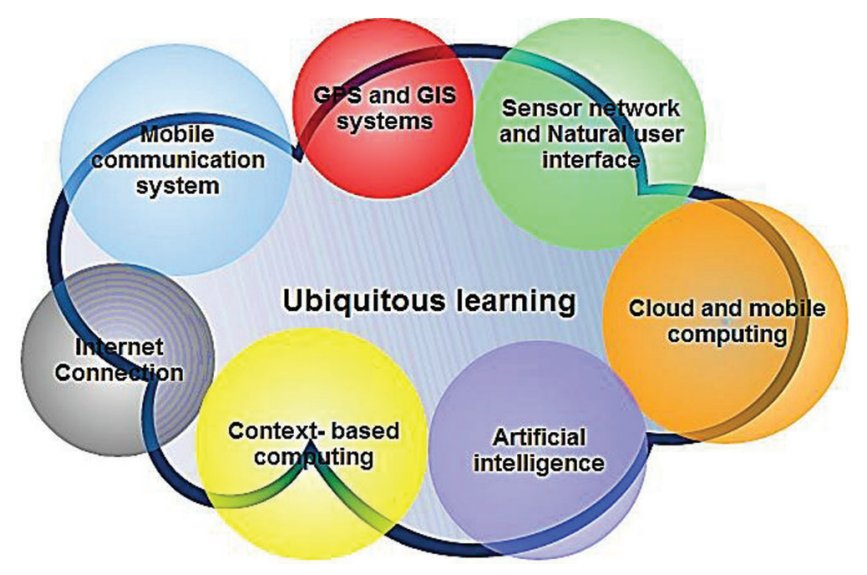

Figure 1: U-learning components

\section{U-learning Characteristics}

The researchers have defined six features of M-learning that have been embedded in the U-learning characteristics, which include (1) urgent need of learning, (2) knowledge acquisition plan, (3) the learning 
environment mobility, (4) the learning process interaction, (5) instructional activity situation, and (6) instructional content integration [17]. Other researchers have presented the U-learning characteristics based on five key factors including accessibility, immediacy, interactivity, permanency, and instructional [18]. When researchers studied the use of ubiquitous computing and context-aware technologies in learning environments, they added other characteristics of U-learning such as self-regulated, adaptive, and community learning [19]. The researchers considered some overlaps between the above characteristics and proposed these combinations as follows: (1) Accessibility, in which the information is usable by as many learners as possible; (2) Immediacy, where learners can gain the information they need at any time; (3) Interactivity, where there can be effective interaction between the learners and their peers and teachers through different tools; (4) Permanency, in which the information remains available until the learners remove it; (5) Context-awareness, where the environment adaptation with learners' situation takes place to provide appropriate information [20].

Recently, researchers represented U-learning as an integrated and attractive model used by instructors, including the following learning methods [21]:

i) Blended learning refers to the union of traditional and electronic learning (i.e., the union of reallife and virtual learning).

ii) Distance learning refers to a remote learning method, where the interaction with the professor is through a screen instead of face-to-face interaction.

iii) Service-learning refers to the application of learned skills in real-life situations as a part of the learning process, as well as translating the learned skills of learners into action and behavior.

iv) Socio-emotional learning refers to the special learning in which an individual learns to recognize, control, and respond to emotions.

v) Situated learning refers to a way of creating learning content from real-life activities in the surrounding environment. Some examples of situated learning activities include (1) field trips, where students actively participate in a practical environment other than their learning environment; (2) cooperative education, in which students join in an actual work environment for practical training; (3) physical education, such as music and sports sessions; (4) laboratories, where students actively participate in practical classrooms such as biology, physics, chemistry, and computer labs

\section{The Challenges of Services' Transformation in KSA due to COVID-19}

In addition to the curfew, the Saudi education responsible has declared a group of procedures targeted to contain the outbreak of the COVID-19 pandemic. One of these procedures was to close all schools and universities in KSA. The government has guaranteed the continuation of the learning process through the provision of U-learning. The Kingdom has used U-learning as an alternative that is implemented through accredited platforms such as the Blackboard Learning Management System (LMS), to ensure that the educational process continues in an effective, interactive, collaborative, and high-quality way. Most Saudi universities such as King Khalid University, and King Saud University, and many others have a full E-learning system platform. The use of U-learning technologies is so important to save time and the health of students in this critical situation. The Saudi Ministry of Education has directed the education process by U-learning, making use of the LMSs provided through the universities' portals. The U-learning systems provide an interactive learning environment, allowing students to interact with their teachers at any time, and provide students with learning activities that aim to promote the students' understanding and skills. On the other hand, the U-learning platforms provide students with various tools to measure and evaluate their understanding of their courses such as exams, projects, forums, essays, presentations, and laboratory. In this paper, the researchers present how these tools can affect student 
understanding, skill, and evaluation positively [22]. In continuation of the preventive procedures to monitor the diffusion of Coronavirus disease in the Kingdom, and according to WHO's (World Health Organization's) declaration of COVID-19 as a universal pandemic, the Saudi government decided to suspend attendance at workplaces in all institutions from the $1^{\text {st }}$ of March 2020.

\section{King Khalid University Plan due to the Spread of COVID-19}

From 1 March 2020, and due to the spread of COVID-19 globally, King Khalid University changed the teaching methodologies. As a result, the university offers a variety of electronic training courses, workshops, and seminars for faculty members and teaching assistants, through Zoom and Blackboard Ultra platforms. The Deanship of E-learning at KKU provides these training courses weekly and announces them via an official email or by sending SMS to the faculty members. The Deanship of E-learning at KKU proposed the transfer plan to a full E-learning system as follows:

i) Determine the number of assessments and divide them by the number of remaining weeks with at least one evaluation weekly (the academic staff should take into consideration the variety of assessments).

ii) Distribute the grades to the number of evaluations such that the final grade of the course should be met.

iii) Publish the assessments plan to the students, by showing grades via the "announcement" and "start here" pages and make sure that the idea is communicated adequately and coherently to all students.

iv) Apply continuous monitoring during and after each evaluation, and then give feedback on the student's performance for each assessment.

\section{British University in Egypt-BUE Policy to avoid the Spread of COVID-19}

The Egyptian Prime Minister extended Egypt's nationwide curfew until last May. As a result, all the BUE buildings were closed at least until that date, and the teaching process continued with the university contingency plan for learning and teaching. The BUE decided that all the education processes must be held online. The academic staff was obligated to attend the class to ensure that the teaching process continues online transparently and effectively. The BUE completely understands the fact that this new situation could be disconcerting to most students. However, this was a necessary procedure, and the university is committed to both following the Egyptian government's recommendations and at the same time helping students to achieve their courses and tasks. So, the BUE decided to apply its emergency plan for preserving interactive and collaborative learning during the Covid-19 pandemic. During this period of closure, teaching and learning will continue relying on the BUE E-learning system using Moodle. Microsoft Class Notes and Microsoft Team software were also used. Module leaders and teaching assistants were available online at the times in which lectures, classes, and tutorials were scheduled before the closure. They were also available during office hours. Laboratories and other practical sessions requiring students to be on campus, or to interact on a face-to-face basis, were postponed until after reopening the campus. Furthermore, the BUE decided to make a recovery plan, in which students carried out all course activities by using Moodle LMS.

\section{Methodology}

This research study uses qualitative and purposive sampling methods. A sample of 600 undergraduate CS students registered in different courses is selected. The paper aims to study and discuss the students' responses towards their usage of U-learning technology for effective learning during the Coronavirus pandemic. 


\section{The Proposed Model and Research Hypotheses}

The researchers propose a UTAUT model to analyze and assess the factors that affect the intention and behavior of learners for accepting the U-learning technology for full E-learning. In addition to the four external variables (age, gender, and experience, and voluntariness), the proposed paradigm depends on the following factors (PE, EE, SI, FC, and BI) as shown in Fig. 2:

- PE represents the status in which learners realize that applying a new technology will support them in performing a valuable score in their job. The PE predictive factor is affected by age, gender, and experience.

- EE represents the degree of easiness related to applying new technology. The EE factor is expected to be more distinguished in the early period of every behavioral intention for the use of the U-learning apps by students for learning and communication.

- SI represents how one person may cause a change in another's behavior. The SI factor relies on the amount of change one beliefs happened to himself/herself as well as his/her relationships with the influencer, other people, and society. This factor can directly affect the intention of a person to use a new system or technology. Teachers, friends, and peers can influence the overall behavior of the students.

- FC refers to the learners' confidence in the availability of integrated infrastructure for empowering them to use the new U-learning technology. The FC factor has a positive relationship with technology usage, according to the UTAUT model.

- BI refers to the strength of learners' intention to do a specific behavior.

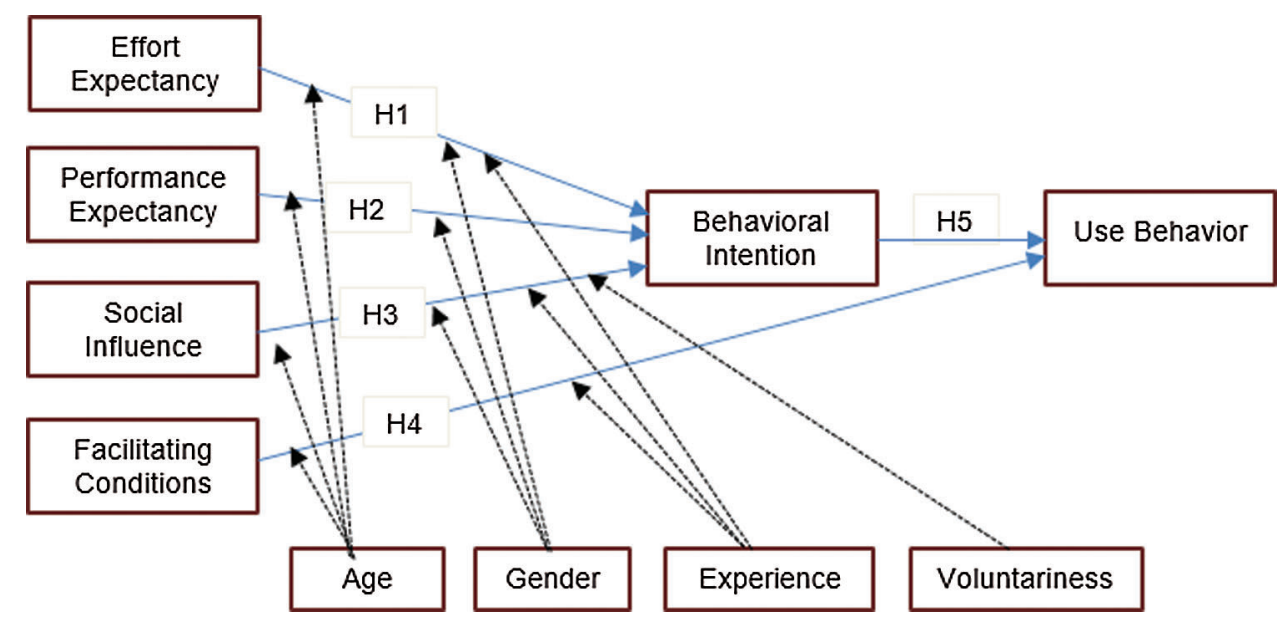

Figure 2: The proposed UTAUT model

The study shows that the effort expectancy will be more distinguished in the embryonic period of all behavioral intention to apply U-learning for full E-learning. It is also predicted that increasing degrees of ease to apply the U-learning will also increase the behavioral intention to use it. Experienced users are shown to be less influenced by the ease of using computers and mobile for access to U-learning. The researchers propose the following hypotheses (see Fig. 2):

- H1: EE positively affects behavioral intentions to apply U-learning for effective learning at KKU and BUE.

- H2: PE positively affects students' behavioral intention to apply U-learning for effective learning.

- H3: SI positively influences the behavioral intentions of KKU and BUE students to apply U-learning for effective learning. 
- H4: FC directly influences KKU and BUE students' behavior to apply U-learning for effective learning.

- H5: BI directly influences KKU and BUE students' behavior to apply U-learning for effective learning.

\section{Research Experiments and Data Analysis}

The authors collected and analyzed the experimental data of this study, using a questionnaire that consists of two parts. The $1^{\text {st }}$ part was designed as a 6-point Likert scale, while the $2^{\text {nd }}$ was implemented to collect the demographic information of the learners. In the Likert scale, (1) and (5) represent Strongly Agree and Strongly Disagree, respectively, while (2), (3), and (4) represent Agree, Neither Agree nor Disagree, and Disagree, respectively. Adding to this, (6) represents Not Applicable. 600 students participated in the online questionnaires with an answer rate of $99.50 \%$.

Tab. 1 shows about $86.7 \%$ of the students apply U-learning for effective E-learning more than once per day, and about $11 \%$ of the students apply U-learning more than once per week, and $1.9 \%$ of the students apply U-learning more than once per month, while $0.5 \%$ of the students didn't use the U-learning respectively.

Table 1: The frequency rate of student' responses $(n=600)$

\begin{tabular}{llll}
\hline & & Frequency & $\%$ \\
\hline Gender & Male & 260 & 43.7 \\
Age & Female & 340 & 56.3 \\
& Under 20 & 220 & 36.7 \\
Class levels & $20-22$ & 380 & 63.3 \\
& L1 & 90 & 15 \\
& L2 & 130 & 21.7 \\
& L3 & 130 & 21.7 \\
Applying U-learning for effective learning & L4 & 140 & 23.3 \\
& L5 once per day & 110 & 16.7 \\
& $\geq$ once per week & 520 & 86.7 \\
& $\geq$ once month & 7 & 11.0 \\
& Just Once per a month & 4 & 1.2 \\
& Didn't use it & 3 & 0.7 \\
\hline
\end{tabular}

The first ten questionnaire questions of the research study are listed below. Tab. 2 presents the Likert scale percent of the given questions:

Q1 What is your evaluation of the learning transformation process to the virtual classrooms due to the spread of the new coronavirus?

Q2 Are there multiple learning benefits for using full E-learning at this stage?

Q3 What is your opinion about the "short tests" assignments provided by the E-learning evaluation methods for each course, through the E-learning system? 
Q4 What is your opinion about the communication and discussion through the "forum" assignments provided by the E-learning evaluation methods for each course, through the E-learning system?

Q5 What is your opinion about the "essay" assignments provided by the E-learning evaluation methods for each course, through the E-learning system?

Q6 What is your opinion about the "project" assignments provided by the E-learning evaluation methods for each course, through the E-learning system?

Q7 What is your opinion about the "survey" assignments provided by the E-learning evaluation methods for each course, through the E-learning?

Q8 What is your opinion about the "presentation" assignments provided by the E-learning evaluation methods for each course, through the E-learning system?

Q9 Are there any challenges facing people, students, institutions, and the country at this stage?

Q10 Are there many different barriers facing your use of E-learning effectively at this stage?

Table 2: Likert scale percent of the first ten questionnaire questions $(n=600)$

\begin{tabular}{lllllll}
\hline Questions & $\begin{array}{l}\text { Strongly } \\
\text { Agree }\end{array}$ & Agree & $\begin{array}{l}\text { Neither Agree } \\
\text { nor Disagree }\end{array}$ & Disagree & $\begin{array}{l}\text { Strongly } \\
\text { Disagree }\end{array}$ & $\begin{array}{l}\text { Not } \\
\text { Applicable }\end{array}$ \\
\hline Q1 & 71.68 & 26.66 & 1.66 & 0 & 0 & 0 \\
Q2 & 40.33 & 48.33 & 8.3 & 3.04 & 0 & 0 \\
Q3 & 50.66 & 36.33 & 5.33 & 4.66 & 1.33 & 1.69 \\
Q4 & 45.33 & 33.33 & 10 & 5 & 3 & 3.34 \\
Q5 & 36.66 & 11.68 & 20 & 1.66 & 25 & 5 \\
Q6 & 41.33 & 41.33 & 4.33 & 4.01 & 6 & 3 \\
Q7 & 40.66 & 38.35 & 6.34 & 4.66 & 1.66 & 8.33 \\
Q8 & 40.31 & 38.4 & 5.3 & 3.66 & 9.33 & 3 \\
Q9 & 41.1 & 56.1 & 1.47 & 1.33 & 0 & 0 \\
Q10 & 39.75 & 51.6 & 1.66 & 3.66 & 3.33 & 0 \\
Mean & 44.781 & 38.211 & 6.439 & 3.168 & 4.965 & 2.436 \\
Std. & 10.18 & 12.81 & 5.55 & 1.66 & 7.65 & 2.73 \\
Deviation & & & & & & \\
\hline
\end{tabular}

Tab. 2 illustrates that the total mean of students that agree to the transformation process to U-learning technology is $82.99 \%$, and the total mean of students that disagreeing is $8.13 \%$, while the total mean of those who neither agree nor disagree is $6.44 \%$. Fig. 3 presents that most of all students consider that applying U-learning has multiple benefits as an effective tool for interactions between students and professors during the spread of COVID-19.

Tab. 3 presents the descriptive analysis for the UTAUT constructs. The mean values for PE, EE, SI, FC, BI, and UB indicators are $\geq 8.0$ and $\leq 9.3$, which implies that most of the students' responses were either Strongly Agree or Agree. This result provided an additional understanding of the issues surrounding the acceptance of using U-learning for full E-learning through the period of Covid-19 spread, using the introduced UTAUT model. The research results presented in Tab. 3 and Fig. 4 show that in addition to 
the UTAUT factors, the BI factor has the highest effect and significantly influences learners' behavioral intention for applying U-learning for effective and learning.

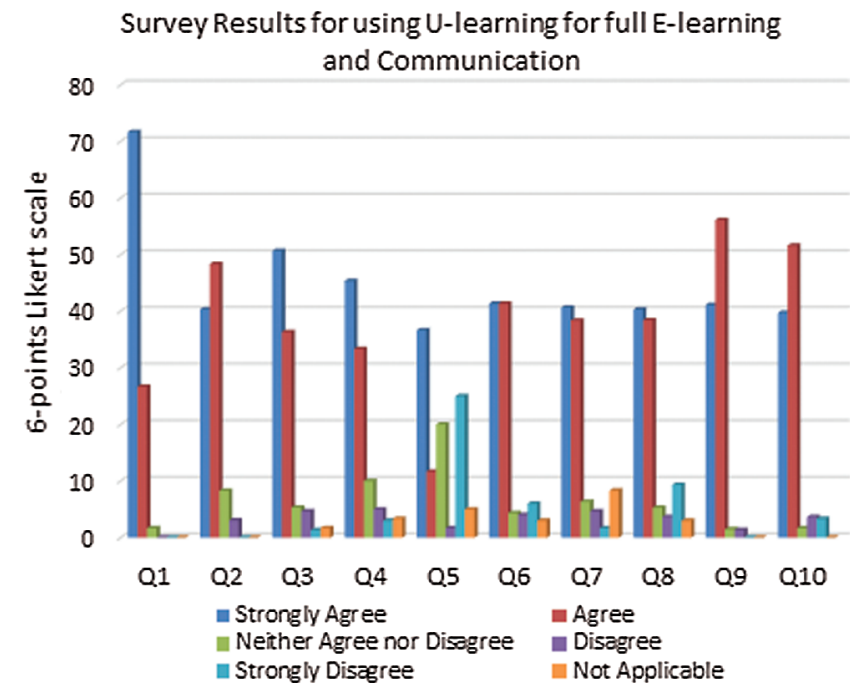

Figure 3: The survey results of using U-learning for learning and communication

Table 3: Data analysis for U-learning adoption using UTAUT indicators

UTAUT indicators
Mean Std

Deviation

PE1: I found the use of U-learning provided by the university so useful to my study. $8.5 \quad 1.83$

PE2: Using the U-learning system (e.g., Blackboard or Moodle) provided by the $\begin{array}{lll}8.3 & 1.82\end{array}$ university increased my productivity.

PE3: Using the U-learning system provided by the university increased my chances $9.1 \quad 1.85$ of getting a very good grade.

EE1: I found using U-learning is so clear and understandable. $\quad \begin{array}{ll}9.2 & 1.91\end{array}$

EE2: I found it easy to become skillful when using U-learning. $\quad 8.3 \quad 1.82$

EE3: I found it easy to use my mobile via the interactive web-conferencing apps $\quad \begin{array}{lll}9.3 & 1.91\end{array}$ provided by the university (i.e., Blackboard or Moodle)

EE4: Learning to operate interactive web-conferencing apps provided by the $\quad \begin{array}{lll}8.7 & 1.85\end{array}$ university was easy for me.

SI1: My professors at the university helped me in the use of the U-learning system. $8.2 \quad 1.91$

SI2: My friends believe that I should use the effective U-learning apps provided by $8.4 \quad 2.01$ the university through mobile.

FC1: I have the necessary resources to apply the U-learning apps (via Blackboard or $8.8 \quad 1.93$ Moodle).

FC2: There is team-work available to solve any problem facing me while using the 8.0

2.05 U-learning apps 


\begin{tabular}{lcc}
\hline Table 3 (continued). & & \\
\hline UTAUT indicators & Mean $\begin{array}{l}\text { Std. } \\
\text { Deviation }\end{array}$ \\
& 8.9 & 1.68 \\
BI1: I intend to apply the U-learning technology in the coming semesters. & 5.6 & 1.82 \\
BI2: I see that I will apply the U-learning apps provided in the coming semesters. & 8.7 & 1.68 \\
BI3: I plan to apply the U-learning apps in the coming semesters. & 8.9 & 1.89 \\
UB1: I will use the U-learning technology as effective learning in the class or at any & & \\
place. & & \\
UB2: I apply the U-learning apps for accessing learning materials whenever and & 9.1 & 1.95 \\
wherever I need them. & & \\
\hline
\end{tabular}

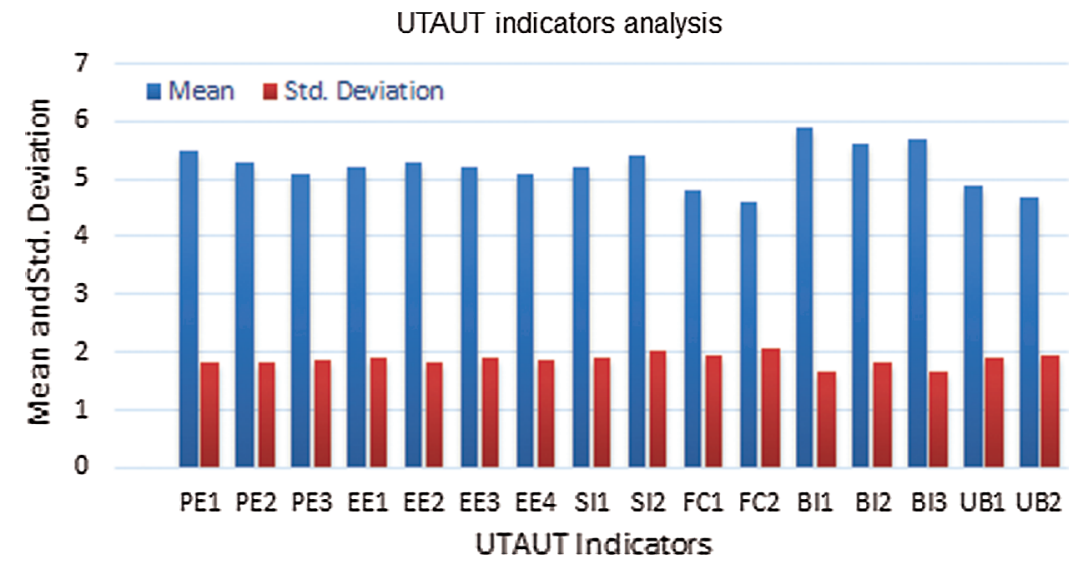

Figure 4: The indicator analysis for applying U-learning during Covid-19 pandemic

\section{Results Analysis and Discussion}

The research sample in this study is created from selected courses taught through the $1^{\text {st }}$ Term of the academic year 2019/2020. The selected courses were applied using the U-learning system during the coronavirus pandemic. The paper aims to discuss the benefits of using U-learning as an effective learning system and present its effect on students' skills. The Online questionnaires were created through the "survey" tool in the Blackboard system and distributed among students in 7 computer science courses with different levels. Eq. (1) is used to evaluate the percentage $P_{i}$ for each question answered in the survey (where $i$ is the number of questions from 1 to 26):

$P_{i}=\frac{f_{i}}{\sum_{i=1}^{n} f_{i}} * 100 \%$

where, $f_{i}$ is the frequency of answers in each attempt.

Eqs. (2) and (3) were used to measure both the composite reliability (CR) and average variance extracted (AVE) of the presented model. 
$C R=\frac{\left(\sum_{i=1}^{n} L_{i}\right)^{2}}{\left(\sum_{i=1}^{n} L_{i}\right)^{2}+\sum_{i=1}^{n} \operatorname{Var}\left(e_{i}\right)}$

$A V E=\frac{\left(\sum_{i=1}^{n} L_{i}\right)^{2}}{n}$

where $n$ is the number of indicators, $L_{i}$ is the loading factor of indicator $i$, and $\operatorname{Var}\left(e_{i}\right)=\left(1-L_{i}^{2}\right)$ represent the variance of the error of indicator $i$.

The average variance extracted was measured to test the effectiveness of the UTAUT paradigm depending on the effective indicators of (PE, EE, SI, FC, BI, and UB). Tab. 4 shows the experimental results used to evaluate the value of $\mathrm{CR}$, and AVE of the presented model. The results have shown that factor loadings $\geq 0.75, \mathrm{CR}$ (PE, EE, FC, BI, UB) $\geq 0.9$ (except $\mathrm{CR}(\mathrm{SI})=0.87$ ), while AVE (PE, EE, SI, $\mathrm{BI}, \mathrm{UB}) \geq 0.75$ (except $\mathrm{AVE}(\mathrm{FC})=0.82$ ). These results matching or exceed the recommended test results and, present appropriate evidence for the soundness and completeness of the proposed model [23].

Table 4: CR and AVE of the proposed UTAUT model

\begin{tabular}{|c|c|c|c|c|c|c|}
\hline Construct & Indicator & $\begin{array}{l}\text { Factor } \\
\text { Loadings }(\lambda)\end{array}$ & $\lambda^{2}$ & $1-\lambda^{2}$ & $\mathrm{CR}$ & AVE \\
\hline \multirow{3}{*}{ PE } & PE1 & 0.791 & 0.63 & 0.37 & \multirow{4}{*}{0.91} & \multirow{4}{*}{0.76} \\
\hline & PE2 & 0.897 & 0.80 & 0.20 & & \\
\hline & \multirow[t]{2}{*}{ PE3 } & 0.926 & 0.86 & 0.14 & & \\
\hline \multirow{5}{*}{$\mathrm{EE}$} & & $\sum=2.614$ & 2.29 & 0.71 & & \\
\hline & EE1 & 0.865 & 0.75 & 0.25 & \multirow{5}{*}{0.93} & \multirow{5}{*}{0.77} \\
\hline & EE2 & 0.887 & 0.79 & 0.21 & & \\
\hline & EE3 & 0.865 & 0.75 & 0.25 & & \\
\hline & \multirow[t]{2}{*}{ EE4 } & 0.901 & 0.81 & 0.19 & & \\
\hline & & $\sum=3.518$ & 3.10 & 0.90 & & \\
\hline \multirow[t]{3}{*}{ SI } & SI1 & 0.856 & 0.73 & 0.27 & \multirow{3}{*}{0.87} & \multirow{3}{*}{0.76} \\
\hline & \multirow[t]{2}{*}{ SI2 } & 0.891 & 0.79 & 0.21 & & \\
\hline & & $\sum=1.747$ & 1.53 & 0.47 & & \\
\hline \multirow[t]{4}{*}{$\mathrm{FC}$} & $\mathrm{FC} 1$ & 0.889 & 0.79 & 0.21 & \multirow{3}{*}{0.90} & \multirow{3}{*}{0.82} \\
\hline & \multirow[t]{2}{*}{$\mathrm{FC} 2$} & 0.921 & 0.85 & 0.15 & & \\
\hline & & $\sum=1.81$ & 1.64 & 0.36 & & \\
\hline & BI1 & 0.815 & 0.66 & 0.34 & \multirow{4}{*}{0.90} & \\
\hline \multirow[t]{4}{*}{ BI } & $\mathrm{BI} 2$ & 0.901 & 0.81 & 0.19 & & \multirow{3}{*}{0.75} \\
\hline & \multirow[t]{2}{*}{$\mathrm{BI} 3$} & 0.878 & 0.77 & 0.23 & & \\
\hline & & $\Sigma=2.594$ & 2.25 & 0.75 & & \\
\hline & UB1 & 0.789 & 0.62 & 0.38 & \multirow{4}{*}{0.90} & \multirow{4}{*}{0.75} \\
\hline \multirow[t]{3}{*}{ UB } & UB2 & 0.841 & 0.71 & 0.29 & & \\
\hline & UB3 & 0.952 & 0.91 & 0.09 & & \\
\hline & & $\sum=2.582$ & 2.24 & 0.76 & & \\
\hline
\end{tabular}


Tab. 5 shows the statistical results of the selected courses taught by U-learning technology during the Covid-19 pandemic period. Each course has six assignments and activities including exams, projects, forums, essays, presentations, and laboratories. Tab. 5 presents for each selected course: the course assignment, the number of students, minimum, maximum, mean, median, standard deviation, and variance of students' grades in each assignment.

Table 5: Statistical results of selected courses taught by U-learning during COVID-19

\begin{tabular}{|c|c|c|c|c|c|c|c|c|}
\hline Course & Assignment & Count & $\begin{array}{l}\text { Min } \\
\text { value }\end{array}$ & $\begin{array}{l}\text { Max } \\
\text { value }\end{array}$ & Mean & Median & $\begin{array}{l}\text { Standard } \\
\text { deviation }\end{array}$ & Variance \\
\hline \multirow{5}{*}{ CSM 215-Operating System 1} & Forum & 67 & 5 & 10 & 12.09 & 15.00 & 3.55 & 12.62 \\
\hline & Essay & 67 & 2 & 9 & 3.46 & 3.00 & 1.34 & 1.80 \\
\hline & Project & 60 & 3 & 15 & 10.47 & 11.00 & 2.42 & 5.85 \\
\hline & $\begin{array}{l}\text { Short } \\
\text { Test\#1 }\end{array}$ & 67 & 2 & 10 & 9.84 & 10.00 & 1.22 & 1.48 \\
\hline & Final Exam & 67 & 16 & 20 & 19.1 & 19 & 0.92 & 0.85 \\
\hline \multirow{5}{*}{ CSM 334-Computer Graphics } & Forum & 59 & 2 & 10 & 9.53 & 10.00 & 1.82 & 3.30 \\
\hline & Essay & 59 & 2 & 8 & 4.10 & 4.00 & 1.54 & 2.36 \\
\hline & Project & 60 & 11 & 18 & 15.60 & 15.00 & 1.28 & 1.64 \\
\hline & $\begin{array}{l}\text { Short } \\
\text { Test\#1 }\end{array}$ & 60 & 8 & 10 & 9.90 & 10.0 & 0.35 & 0.12 \\
\hline & Final Exam & 60 & 14 & 20 & 19.05 & 19 & 1.09 & 1.19 \\
\hline \multirow{5}{*}{$\begin{array}{l}\text { CSM 371-Software } \\
\text { Engineering I }\end{array}$} & Forum & 53 & 2 & 10 & 9.66 & 10.00 & 1.33 & 1.77 \\
\hline & Essay & 55 & 4 & 8 & 3.75 & 3.00 & 1.79 & 3.21 \\
\hline & Project & 53 & 12 & 14 & 12.60 & 11.00 & 1.21 & 1.35 \\
\hline & $\begin{array}{l}\text { Short } \\
\text { Test\#1 }\end{array}$ & 54 & 8 & 10 & 9.90 & 10.0 & 0.36 & 0.13 \\
\hline & Final Exam & 53 & 17 & 20 & 19.39 & 20 & 0.77 & 0.59 \\
\hline \multirow{5}{*}{$\begin{array}{l}\text { CSM 476-Expert System and } \\
\text { Knowledge Engineering }\end{array}$} & Forum & 49 & 5 & 15 & 13.45 & 15.00 & 2.82 & 7.96 \\
\hline & Essay & 45 & 4 & 11 & 8.11 & 8.00 & 2.34 & 5.48 \\
\hline & Project & 49 & 5 & 14 & 11.59 & 12.00 & 2.23 & 4.98 \\
\hline & $\begin{array}{l}\text { Short } \\
\text { Test\#1 }\end{array}$ & 49 & 8 & 10 & 9.90 & 10.0 & 0.35 & 0.12 \\
\hline & Final Exam & 49 & 14 & 20 & 18.61 & 19 & 1.32 & 1.75 \\
\hline \multirow{5}{*}{$\begin{array}{l}\text { ISM-CS 362-Computing } \\
\text { Ethics and Society }\end{array}$} & Forum & 40 & 5 & 10 & 9.80 & 10.00 & 0.81 & 0.66 \\
\hline & Essay & 39 & 4 & 11 & 8.28 & 8.00 & 2.24 & 5.02 \\
\hline & Project & 41 & 11 & 19 & 15.66 & 15.00 & 1.93 & 3.74 \\
\hline & $\begin{array}{l}\text { Short } \\
\text { Test\#1 }\end{array}$ & 40 & 9 & 10 & 9.95 & 10.00 & 0.22 & 0.05 \\
\hline & Final Exam & 41 & 13 & 20 & 17.54 & 18.00 & 1.78 & 3.18 \\
\hline
\end{tabular}


Figs. 5 and 6 present the result analysis of operating system and computer graphics courses, respectively, in the forum, essay, project, short tests, and final exam assignments out of 80. Fig. 5 shows that there are 67 students registered in the operating system course who completed the forum assignment with a minimum score of 5 , and a maximum score of 10 , with the largest standard deviation value of 3.55. The same students completed the final exam assignment with a minimum score of 16 out of 20 , and a maximum score of 20 , with the smallest standard deviation value of 0.29 .

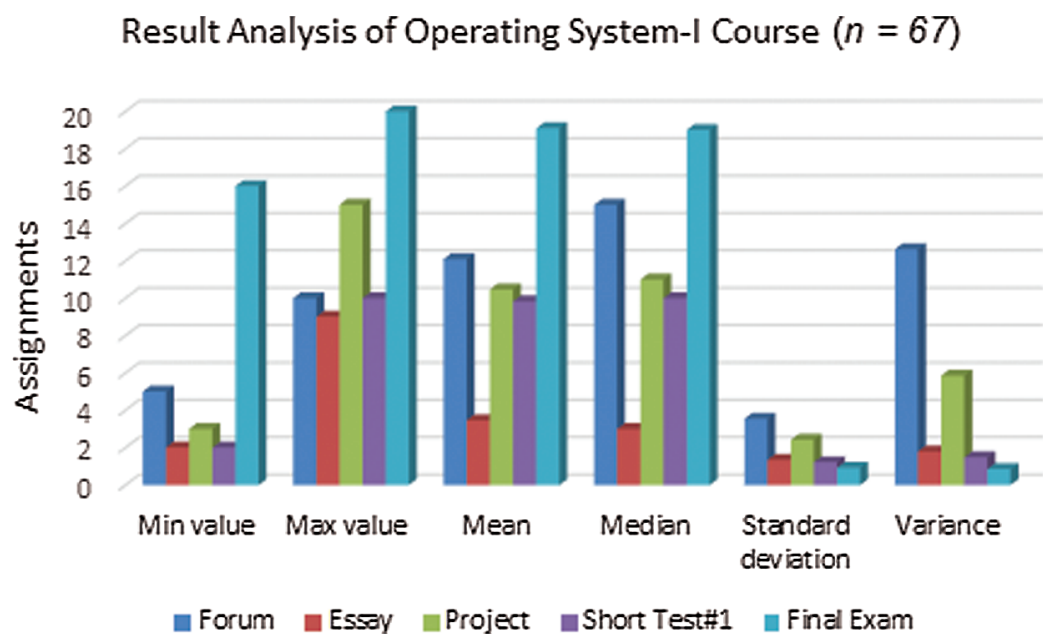

Figure 5: Result analysis of operating system course

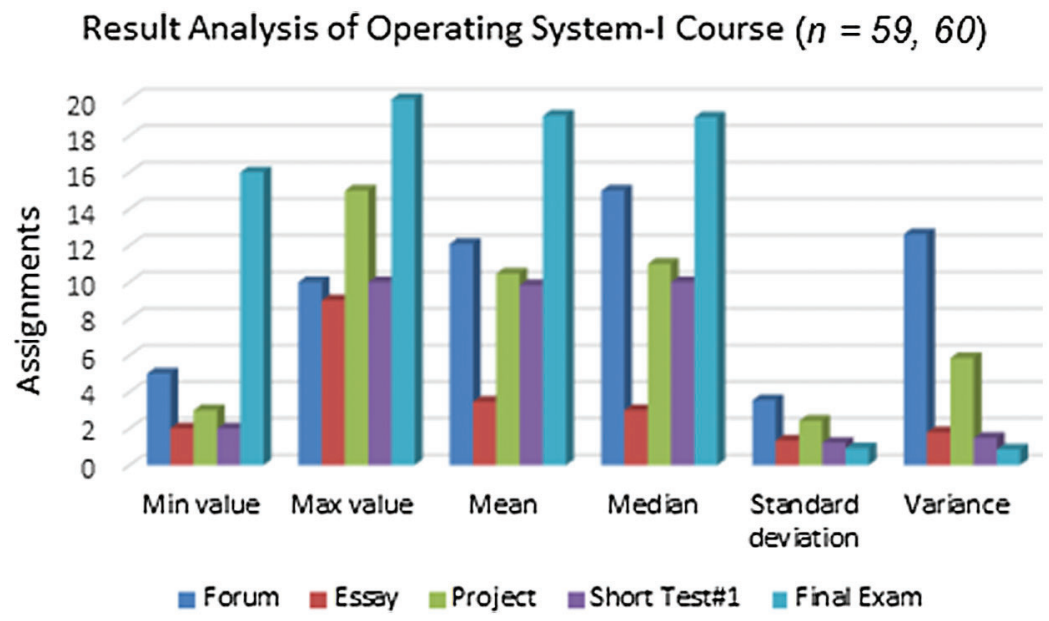

Figure 6: Result analysis of computer graphics course

Fig. 6 shows that there are 59 students registered in the computer graphics course who completed the forum assignment with a minimum score of 2 , and a maximum score of 10 , with the largest standard deviation value of 1.82. There are 60 students of the same course who completed the short test\#1 assignment with a minimum score of 8 out of 10 , and a maximum score of 10 , with the smallest standard deviation value of 0.35 . 
Fig. 7 presents the histogram of the result analysis of the computer graphics course out of 100 . The histogram presents the statistical indicators of the result analysis of the course including the arithmetic mean for students' grades in the course (i.e., 90.79). This means that the general average is high, indicating a high level in students' grades. The standard deviation is a measure that means a set of grades deviates from the mean, which is equal to $5.232<$ mean (see Fig. 7). Therefore, the deviation of the grades is less within the data set. Fig. 7 also shows that the curve tends to have a relatively negative skew, which indicates the high grades of some students (skewness $=-2.231$ ).

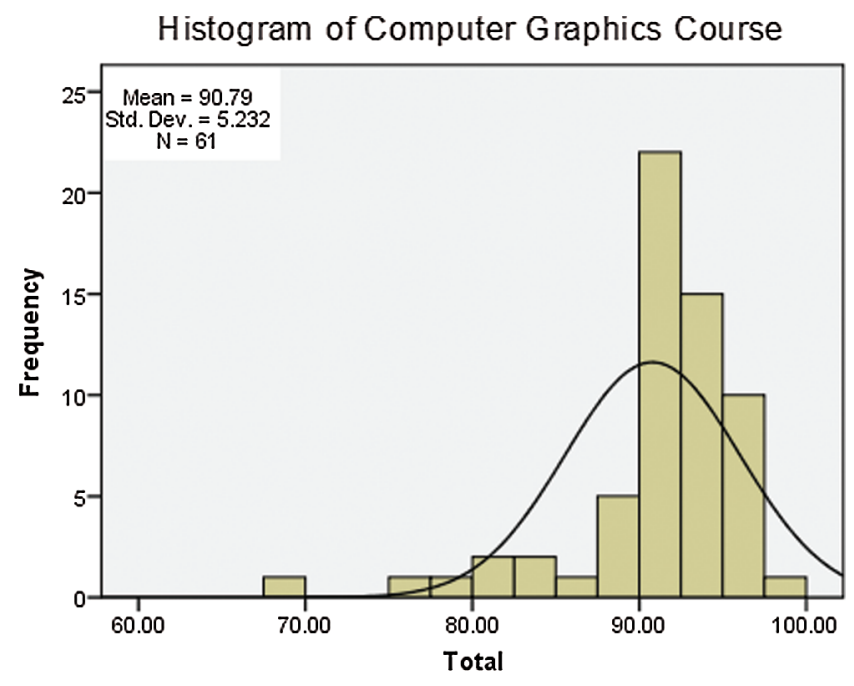

Figure 7: Descriptive statistics of computer graphics

\section{Conclusion}

This paper presented a qualitative evaluation regarding the usage of U-learning instead of conventional education and basic learning process to prevent the spread of the Coronavirus. The researchers introduced a new UTAUT model to evaluate the impact of the indicated factors on the students' intention and behavior regarding the usage of the U-learning technique for full E-learning. The study has shown possibly positive effects of using U-learning apps for implementing their learning activities now and in the future. The researchers also presented the descriptive statistics affecting the student results using U-learning while implementing learning assignments including exams, projects, forums, essays, presentations, and laboratories. The research experiments demonstrated both the composite reliability and the average variance extracted from the presented model. The experimental results have shown that (1) the factor loadings $\geq 0.75, \mathrm{CR} \geq 0.9$, and $\mathrm{AVE} \geq 0.75$, which present appropriate proof for the effectiveness and reliability of the proposed UTAUT model, and (2) the total average of students that accept the U-learning is $82.99 \%$, and who disagree is $8.13 \%$, while who neither agree nor disagree is $6.44 \%$.

Acknowledgement: The author extends his appreciation to the Deanship of Scientific Research at King Khalid University for funding this work through General Research Project under grant number (GRP-3540/2019).

Funding Statement: The authors received funding for this study from King Khalid University, grant number (GRP-35-40/2019). 
Conflicts of Interest: The authors declare that they have no conflicts of interest to report regarding the present study.

\section{References}

[1] K. Sakamura and N. Koshizuka, "Ubiquitous computing technologies for ubiquitous learning," in Proc. of the IEEE International Workshop on Wireless and Mobile Technologies in Education (WMTE'05), Tokushima, Japan, pp. 11-20, 2005.

[2] V. Venkatesh, M. Morris, G. Davis and F. Davis, "User acceptance of information technology: Toward a unified view," MIS Quarterly, vol. 27, no. 3, pp. 425-478, 2003.

[3] M. Weiser, "The computer of the $21^{\text {st }}$ century," Scientific American, vol. 265, no. 3, pp. 66-75, 1991.

[4] C. Schank, "What we learn when we learn by doing," Institute for the Learning Sciences Northwestern University, Technical, Report, no. 60, 2009.

[5] Y. S. Chen, T. C. Kao, J. P. Sheu and C. Y. Chiang, "A mobile scaffolding-aid-based bird-watching learning system", in Proc. of IEEE International Workshop on Wireless and Mobile Technologies in Education (WMTE'02), Vaxjo, Sweden, pp. 15-22, 2002.

[6] T. Uemukai, T. Hara and S. Nishio, "A method for selecting output data from ubiquitous terminals in a ubiquitous computing environment," in Proc. of the 24th Int. Conf. on Distributed Computing Systems Workshops (ICDCSW'04), Tokyo, Japan, pp. 562-567, 2004.

[7] T. Z. Yang, F. R. Kuo, J. G. Hwang and H. C. Chu, "A computer assisted approach for designing context-aware ubiquitous learning activities", in Proc. of IEEE Int. Conf. on Sensor Networks, Ubiquitous and Trustworthy, Taichung, Taiwan, pp. 1-8, 2008.

[8] K. Liyytinen and Y. Yoo, "Issues and challenges in ubiquitous computing," Communications of the ACM, vol. 45, no. 12, pp. 62-65, 2002.

[9] G. J. Hwang, C. C. Tsai and S. J. H. Yang, "Criteria, strategies and research issues of context-aware ubiquitous learning," Educational Technology \& Society, vol. 11, no. 2, pp. 81-91, 2008.

[10] H. Ogata and Y. Yano, "Context-aware support for computer-supported ubiquitous learning," in Proc. of the 2nd IEEE Int. Workshop on Wireless and Mobile Technologies in Education, JungLi, Taiwan, pp. 27-34, 2004.

[11] O. K. Boyinbode and K. G. Akintola, "A sensor-based framework for ubiquitous learning in Nigeria," IJCSNS International Journal of Computer Science and Network Security, vol. 8, no. 11, pp. 401-405, 2008.

[12] D. Casey, "U-learning = e-learning + m-learning," in Proc. of World Conf. on E-Learning in Corporate, Government, Healthcare, and Higher Education, G. Richards (ed.), Chesapeake, VA: AACE, pp. 2864-2871, 2005.

[13] V. Jones and J. H. Jo, "Ubiquitous learning environment: an adaptive teaching system using ubiquitous technology," In R. Atkinson, C. McBeath, D. Jonas-Dwyer and R. Phillips (eds.), Beyond the Comfort Zone: in Proc. of the 21st ASCILITE Conf., Perth, Australia, pp. 468-474, 2004.

[14] D. Danail and H. Ivo, "Mobile learning applications: Ubiquitous characteristics and technological solutions," Cybernetics and Information Technologies, vol. 6, no. 3, pp. 63-74, 2006.

[15] H. Gwo-Jen, "Criteria and strategies of ubiquitous learning," in Proc. of the IEEE Int. Conf. on Sensor Networks, Ubiquitous, and Trustworthy Computing (SUTC'06), Taichung, Taiwan, 2006.

[16] F. Michael and R. Oliver, "Ubiquitous computing: An overview of technology impacts," Elsevier Telematics and Informatics, vol. 28, no. 2, pp. 55-65, 2011.

[17] L. Cheng and I. Marsic, "Piecewise network awareness service for wireless/mobile pervasive computing," Mobile Networks and Applications (MONET), vol. 17, no. 4, pp. 269-278, 2002.

[18] M. Curtis, K. Luchini, W. Bobrowsky, C. Quintana and E. Soloway, "Handheld use in k-12: A Descriptive Account," in Proce. of IEEE Int. Workshop on Wireless and Mobile Technologies in Education (WMTE'02), Vaxjo, Sweden, pp. 23-30, 2002.

[19] P. S. Chiu, Y. Kuo, Y. Huang and T. Chen, "A meaningful learning based u-learning evaluation model," in Proc. of the 8th. IEEE Int. Conf. on Advanced Learning Technologies, Santander, Spain, pp. 77-81, 2008. 
[20] Y. Saadiah, A. Erny and A. Kamarularifin, "The definition and characteristics of ubiquitous learning: A discussion," International Journal of Education and Development using Information and Communication Technology (JEDICT), vol. 6, no. 1, pp. 117-127, 2010.

[21] S. Shafaq, W. Ahmad, M. Abdul Rehman, Q. Faiza and G. Marina, "U-Learning: A Modern Paradigm Shift of Learning from Higher Education Students' Perspective," in Proc. of the Int. Conf. on Information and Communication Technology for the Muslim World, 978-1-5386-7525-0/18, Kuala Lumpur, Malaysia, pp. 191-195, 2018.

[22] Arab News, 2020. [Online]. Available: https://www.arabnews.com/node/1637821/saudi-arabia.

[23] F. Joseph, C. William, J. Barry and E. Rolph, Multivariate data analysis, 7th ed. Englewood Cliffs, NJ: PrenticeHall, 2010. 